\title{
Information Systems of Forecasting Incidence Rates of Dengue Fever Disease Using Multivariate Fuzzy Time Series
}

\author{
Ardian Fakhru Rosyad ${ }^{1 *}$, Farikhin ${ }^{2}$, Jatmiko Endro Suseno ${ }^{3}$. \\ ${ }^{1}$ Master Program of Information System, Diponegoro University, Semarang, Indonesia. \\ ${ }^{2}$ Department of Mathematics, Faculty of Sains and Matematics, Diponegoro University, Semarang, \\ Indonesia. \\ ${ }^{3}$ Department of Physics, Faculty of Sains and Matematics, Diponegoro University, Semarang, \\ Indonesia.
}

\begin{abstract}
Demak Regency is one of the regions in Central Java Province with a low incidence of Dengue Fever compared to other cities and districts. Even so, DHF control needs to be done to minimize the occurrence of dengue fever, because DHF is a fairly dangerous disease. One form of controlling the number of DHF events that is widely used is using forecasting models, one of them is using Fuzzy Time Series. The Multivariate Fuzzy Time Series (MFTS) model is a development of the Fuzzy Time Series model that can be used to forecast using time series data by using more than one variable for forecasting, compared to the Fuzzy Time Series method that usually using only one variable. Based on the research results obtained, the MFTS model has a fairly accurate MAPE value, wherein the best MAPE was at 3 years scenario with MAPE 10,728\%.
\end{abstract}

\section{Introduction}

Dengue Hemorrhagic Fever or DHF is one of the problems of tropical countries because Dengue Fever is easy to develop in tropical environments, one of which is Indonesia. Indonesia is one of eight Asian countries with the highest potential for spreading DHF cases and ranks third [1] . Central Java is one of the provinces with the most dengue cases for 2017, which is more than 7000 cases in each province. Demak Regency is one of the regions in Central Java Province with a fairly low incidence compared to other cities and districts. According to Demak District health profile data, the number of dengue fever cases in 2013 was 610 cases with a mortality rate of 13 people, in 2014 it had decreased to 427 cases and experienced severe fluctuations in 2015 with dengue incidence reaching 1,009 cases with a total of 25 deaths, until 2018, the number of dengue fever reached 42 cases, with the number of deaths reach 1 person. Even so, the potential area for DHF has precisely experienced an increase compared to 2017 [2].

Many approaches have been taken for DHF surveillance. One approach that is widely used is using forecasting models. DHF forecasting models are generally presented as data per

* Corresponding author: ardianfakhru3@gmail.com 
month because of the phenomenon delays that become one of the factors supporting the incidence of DHF have a close relationship with climate factors, such as temperature, humidity, rainfall and even wind speed [3]. The phenomenon of the delayed spread of DHF can be used as a gap to predict the incidence of DHF based on data in the previous month and provide an opportunity to take preventative measures [4].

Several studies of disease incidence have been done before. As an example of predicting the number of DHF sufferers in Malang, Indonesia, using the Ordinary Least Square linear regression method [5], using genetic algorithm (GA) for optimizing alpha, beta and gamma parameters in the Triple Exponential Smoothing algorithm to predict the incidence of DHF in two Sragen Districts starting in 2016 [6], or using the K-Means method [7].

The fuzzy method is widely applied in various fields, one of which is in the field of DHF surveillance. Among them for early detection of dengue fever using the Fuzzy Inference System [8], using a fuzzy expert system for the detection of patients suspected of suffering from dengue fever [9]. ANFIS is also applied in an expert system for the detection of patients suspected of having DHF [10]. The fuzzy system has several advantages compared to several other methods because fuzzy can process linguistic data, for example, data on the geographic location of the district, high and low temperatures, on the incidence of DHF. Besides that, the system is fuzzy claimed to be faster and more accurate compared to traditional forecasting methods which require a lot of data and a longer time [11].

One of the developments of the fuzzy method is the Multivariate Fuzzy Time Series or MFTS method. MFTS is used because of its advantages in considering many factors in forecasting compared to the usual Fuzzy time series method [12], also, MFTS can be used to predict with a small amount of data, but, the accuracy of MFTS forecasting is also influenced by the amount of data. The less training data used, the better the accuracy of forecasting produced [13]. The MFTS model has been used to forecast reservoir water level estimates using DMA or reservoir water level as the main variable and Inflow and Outflow variables as supporting variables. This research examines the effect of multiple Orders with forecasting accuracy. The results obtained are that the supporting factors and the number of orders can help improve the accuracy of forecasting results because the supporting factors and the number of orders are used for the formation of FLR and FLRG, where the presence of supporting factors and the number of orders can provide more FLRG variations, which can reduce duplication of relations between fuzzy set, and improve the accuracy of prediction results [14].

MFTS was once used to forecast the number of Australian tourists coming to Bali, taking into account the variable number of tourists from July 2009 - June 2014. The research objective was to compare the accuracy of forecasting the FTS method with MFTS in modeling the number of Australian tourists visiting Bali and knowing the predicted number Australian tourists visiting Bali in the following month [15].

Problems that occured in the Demak District Health Office, that is a lot of Incidence of DHF data is still conventionally recorded, also the data that can be taken is limited, so to get the data, Demak District Health Office officials need to look for one by one in the recap of the pretty much data files in the Library. Based on these problems, the MFTS method was chosen for applied to the study of the incidence of DHF for the next month period, because of its advantages in forecasting accuracy with a limited amount of data. With forecasting data, the number of DHF events generated from forecasting using the MFTS method is expected to help health workers in the decision-making process related to preparation for the dengue outbreak the following month. 


\section{Materials and Methods}

The system design is the implementation phase of the MFTS method into the system designed. At this stage the system is implemented into an application that is designed using the php programming language.

\subsection{Multivariate Fuzzy Time Series}

Multivariate fuzzy time series or MFTS is a method development of Fuzzy time series by adding several variables that affect forecasting. This is done to improve forecasting accuracy, because in daily life, an event occurs due to many factors. To get better results in forecasting it is necessary to consider many factors. Data processed in the process of forecasting the incidence of dengue fever using the MFTS model with the following flow [16] :

1. Defining the main factors and supporting factors. In this case, the main factor is the number of DHF events notated by X in the Demak area while supporting factors for the rainfall and rainy days in the Demak area are denoted by $\mathrm{Y}$.

2. After defining the main and supporting factors, the next step is to change the value of the data into a percentage with equation 2.1

$$
\frac{t_{j-} t_{j-1}}{t_{j-1}} \times 100 \%
$$

3. Define the main factor with $U=\left[D_{\min }-D_{1}, D_{\max }+D_{2}\right], D_{\min }$ is the minimum value of data and $D_{\max }$ is the upper value of the maximum value. $D_{1}$ and $D_{2}$ is a positive real random number to divide the universal set into $n$ equal intervals $u_{1}, u_{2}, \ldots . u_{n}$. For supporting factors, define the universal set of supporting factors $V_{i}, i=1,2, \ldots, m-1$ with $V_{i}=\left[\left(E_{i}\right)_{\min }-E_{i 1},\left(E_{i}\right)_{\max }-E_{i 2}\right]$, where $\left(E_{i}\right)_{\min }=$ $\left(E_{1}\right)_{\min },\left(E_{2}\right)_{\min }, \ldots\left(E_{m}\right)_{\min }$ dan $\left(E_{i}\right)_{\max }=\left(E_{1}\right)_{\max },\left(E_{2}\right)_{\max }, \ldots\left(E_{m}\right)_{\max }$ are the minimum and maximum values in each supporting factor data. $E_{i 1}$ dan $E_{i 2}$ are vectors of positive numbers to divide each universal number in the supporting factors $V_{i}, i=$ $1,2, \ldots, m-1$ into equally equal intervals, hereinafter referred to as $v_{1, l}, v_{2, l}, \ldots, v_{m-1, l}, l=1,2, \ldots, p$ with $v_{1,1}, v_{1,2}, \ldots, v_{1, p}$ represent $\mathrm{n}$ intervals of the same length from the set of universes $v_{1}$ for fuzzy time series supporting factors first. The supporting factor interval matrix is denoted as $(m-1) \times l$.

4. After the universe of main factors and supporting factors is defined, the next step is to define the linguistic value of $A_{i}$, as well as the linguistic value of the supporting factors with $B_{i, j}, i=1,2, \ldots, m-1, j=1,2, \ldots, n$, defined by the fuzzy set of the main factors by rules below:

$$
\begin{gathered}
A_{1}=1 / u 1+0,5 / u 2+0 / u 3+0 / u 4+\cdots+0 / u l-2+0 / u l-1+0 / u l \\
A_{2}=0,5 / u+1 / u 2+0,5 / u 3+0 / u 4+\cdots+0 / u l-2+0 / u l-1+0 / u l \\
A_{3}=0 / u 1+0,5 / u 2+1 / u 3+0,5 / u+\cdots+0 / u l-2+0 / u l-1+0 / u l \\
\cdot \\
\cdot \\
\cdot \\
A_{n}=0 / u 1+0 / u 2+0 / u 3+0 / u 4+\cdots+0 / u l-2+0,5 / u l-1+1 / u l
\end{gathered}
$$

5. Next is the time series data fuzzification process for the main and supporting factors, with the main factors notated into the $u l$ interval, and for the first supporting factor notated into the interval $V_{i, 1}$, while for the second supporting factor into the interval $W_{i, 1}$, ,. The main factor fuzzification process starts with finding the interval $u l$, with $l=$ $1,2, \ldots, p$ with the condition : 
Condition 1. If the value of the main factor is in the $u_{1}$ interval, then the value of the main factor is fuzzified to $1 / A 1+0,5 / A 2+0 / A 3$, denoted by $X_{1}$.

Condition 2. If the value of the main factor is in the $u_{l}, l=2,3, \ldots, p-1$ interval, then the value of the main factor is fuzzified to $0,5 / A_{i-1}+1 / A_{i}+0,5 / A_{i+1}$, denoted by $X_{i}$.

Condition 3. If the value of the main factor is in the $u_{p}$ interval, then the value of the main factor is fuzzified to $0 / A_{n-2}+{ }^{0,5} / A_{n-1}+1 / A_{n}$, denoted by $X_{n}$.

6. Form The FLR of the $m$-order factor is based on the fuzzification value of the main factors and supporting factors. The FLR is the form of the $m$-factor of order to rules below:

$\left(X_{j-k} ; Y_{2, j-k}, \ldots, Y_{m-1, j-k}\right), \ldots,\left(X_{j-2} ; Y_{2, j-2}, \ldots, Y_{m-1, j-2}\right)$,

$\left(X_{j-1} ; Y_{1, j-1}, Y_{2, j-1}, \ldots, Y_{m-1, j-1}\right), \rightarrow X_{j}$

with $j>k . X_{j-k}$ shows the dependency $k$-step of the $j$-th value of the main factors $X_{j}, Y_{i}, j-k, \mathrm{i}=1,2, \ldots, m-1, j=1,2, \ldots, k$. The next step for FLR into FLRG is based on the current states of FLR. FLR is divided into FLRG by ordering FLR from the smallest FLR value to the largest FLR value. While supporting factors play a role as supporting components of the $\mathrm{m}$-dimensional vector.

7. Calculate the forecast based on the principles below;

Principle 1. If $\mathrm{m}$ - FLRG k-order factor, with only one FLRG value, is shown in equation 2.9 below:

$$
\begin{aligned}
& \left(X_{j-k} ; Y_{2, j-k}, \ldots, Y_{m-1, j-k}\right), \ldots,\left(X_{j-2} ; Y_{2, j-2}, \ldots, Y_{m-1, j-2}\right), \\
& \left(X_{j-1} ; Y_{1, j-1}, Y_{2, j-1}, \ldots, Y_{m-1}\right), \rightarrow X_{j}
\end{aligned}
$$

Where $X$ is the main factor fuzzification value and $Y$ is the supporting factor fuzzification value, the forecast day-J is calculated in equation 2.2 as follows:

$$
t_{j}=\left\{\begin{array}{cc}
\left(\frac{m 1+0,5 * m 2}{1+0,5}\right) & \text { if } j=1 \\
\left(\frac{0,5 * m_{j-1}+m j+0,5 * m_{j+1}}{0,5+1+0,5}\right) & \text { if } 2 \leq j \leq n-1 \\
\left(\frac{0,5 * m_{n-1}+m n}{0,5+1}\right) & \text { if } j=n
\end{array}\right.
$$

where $m_{j-1}, m_{j}$ and $m_{j+1}$ are the midpoint values of the intervals $u_{j-1}, u_{j}$ dan $u_{j+1}$. The value of $\mathrm{j}$ is the fuzzy set value which is denoted by $n$.

Principle 2. If $\mathrm{m}$ - k-order factor before the i-day, with more than one FLRG value, is shown in below:

$$
\begin{aligned}
& \left(X_{j-k} ; Y_{2, j-k}, \ldots, Y_{m-1, j-k}\right), \ldots,\left(X_{j-2} ; Y_{2, j-2}, \ldots, Y_{m-1, j-2}\right), \\
& \left(X_{j-1} ; Y_{1, j-1}, Y_{2, j-1}, \ldots, Y_{m-1, j-1}\right), \rightarrow X_{j 1}, X_{j 2}, \ldots, X_{j p}
\end{aligned}
$$

Calculate the predicted value using the second principle shown by equation 2.3:

$$
\frac{n_{j-1} * t_{j 1}+n_{j-2} * t_{j 2}+\cdots+n_{j p} * t_{j p}}{n_{j 1}+n_{j 1}+\cdots+n_{k p}}
$$

With the values of $t_{j 1}, t_{j 2}, \ldots$, and $t_{j p}$ refer to the results of $t_{j}$ in principle one.

Principle 3. If $\mathrm{m}$ - the $\mathrm{k}$-order factor with $\mathrm{k} \geq 2$ before i-day with an unknown FLRG value as shown in rules below:

$\left(X_{j-k} ; Y_{2, j-k}, \ldots, Y_{m-1, j-k}\right), \ldots,\left(X_{j-2} ; Y_{2, j-2}, \ldots, Y_{m-1, j-2}\right)$,

$\left(X_{j-1} ; Y_{1, j-1}, Y_{2, j-1}, \cdots, Y_{m-1, j-1}\right), \rightarrow$ \#

Calculate the predicted value using equation 2.4 below:

$$
\frac{1 * t_{i k}+2 * t_{i(k-1)}+\cdots+k * t_{i l}}{1+2+\cdots+k}
$$

With the values of $t_{i k}, t_{i(k-1)}, \ldots, t_{i l}$ refer to the result of principle one. 


\subsection{Validation of Forecasting Accuracy}

A forecasting model that has been done then will be tested for accuracy using several indicators. There are several ways to test the accuracy generated by forecasting. Some of them use RMSE, AFER, MSE and MAPE. MAPE (Mean Absolute Percentage Error) is the average value of the absolute percentage of forecast error by calculating the absolute error value in each period the error value divided by n. MAPE is widely used to measure forecast accuracy because the value generated by MAPE is forecast accuracy in the form of a percentage so that it is easier to read. The MAPE model used is represented by equation 2.5 as follows:

$$
M A P E=\left(\frac{\Sigma\left|\frac{X_{t}-F_{t}}{X_{t}} \times 100\right|}{n}\right) \%
$$

For the MAPE criteria used to measure forecast accuracy, the criteria table according to table 1 is used below:

Table 1. MAPE Criteria.

\begin{tabular}{|c|c|}
\hline MAPE $(\boldsymbol{\%})$ & Forecasting Accuracy \\
\hline$<10$ & Very accurate \\
\hline $10-20$ & Accurate \\
\hline $20-50$ & Quite Accurate \\
\hline$>50$ & Not accurate \\
\hline
\end{tabular}

\section{Research Method}

The Multivariate Fuzzy Time Series model will then be used to predict the incidence of DHF. The steps taken are determining the actual data used for forecasting in the form of DHF incidence, rainfall and rainy days from January 2013 to December 2018. Observation is used to obtain data on the incidence of DHF which can be obtained directly from the Demak District Health Office by conducting a direct interview with one of the Demak District Health Office officials.

The data used to support this research is in the form of data on the incidence of DHF that occurred in Demak Regency, where predictions are made in stages per month, with a range of historical data adjusting the date the forecasting will take place. For supporting variables used rainfall data and rainy days taken from BMKG Semarang for Demak Regency as shown in Table 2:

Table 2. Data for Forecasting.

\begin{tabular}{|c|l|c|c|c|}
\hline Year & Month & Dengue Incidence & Rainfall & Rainy Days \\
\hline 2013 & January & 101 & 397 & 20 \\
\hline 2013 & February & 69 & 220 & 12 \\
\hline 2013 & March & 64 & 404 & 16 \\
\hline
\end{tabular}

\begin{tabular}{|l|l|l|l|c|}
\hline 2018 & October & 1 & 224 & 9 \\
\hline 2018 & November & 4 & 390 & 18 \\
\hline 2018 & December & 4 & 188 & 12 \\
\hline
\end{tabular}


Step by step of the MFTS model is explained as follows:

- Input data from the main variables occurrence of DHF, and supporting variables of Rainfall and Rainy Day.

- Transform data into a percentage form.

- The next stage is the shape of the universe, class intervals and class length.

- The next stage, define fuzzy sets according to the number of intervals formed and fuzzification of data into fuzzy sets.

- $\quad$ The next stage, form FLR and FLRG order 1 to order 5.

- The final step, use FLRG to calculate the forecast value.

\subsection{Design Forecasting Systems}

The system design is the implementation phase of the MFTS method into the system designed. At this stage the system is implemented into an application that is designed using the php programming language.

1. Software Design

The waterfall model or linear sequential model is used to design applications for forecasting DHF occurrences using the Multivariate Fuzzy Time Series method. The designed waterfall model consists of four stages referring to Figure 1

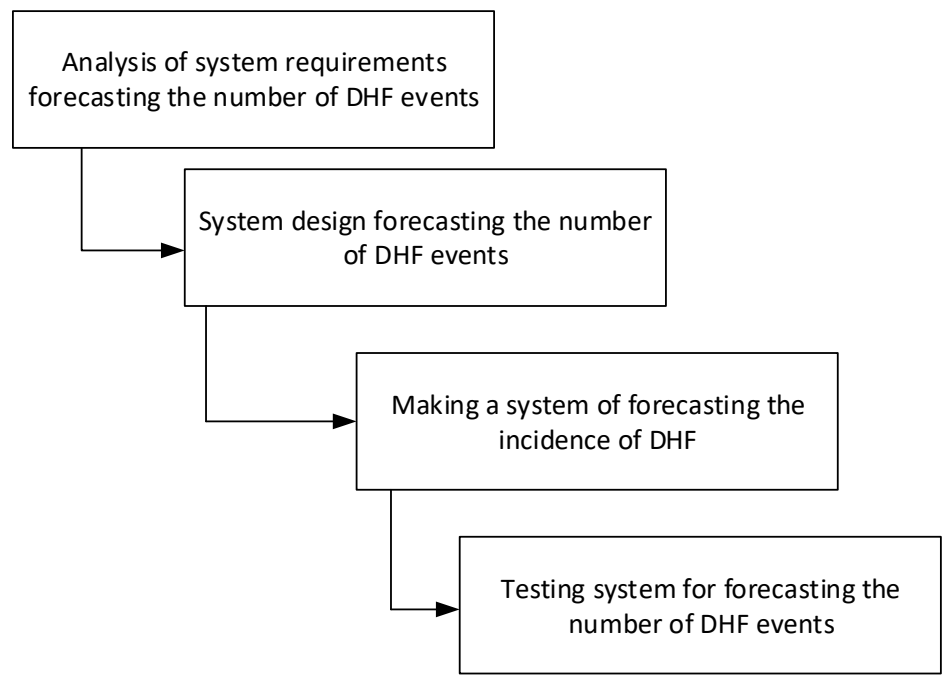

Fig. 1.The Forecasting Waterfall Model.

2. Flow Chart Analysis

Flowchart is used to describe operational processes so that they are easily understood and easily seen based on the sequence of steps from one process to another. In this study, flowchart analysis is used to explain the flow of data in the system designed. The flowchart analysis phase in the system is carried out with two analyzes, including the analysis of ERD (Entity Relationship Diagram) and DFD (Data Flow Diagram).

A. ERD analysis

ERD analysis is carried out with the aim of ensuring database tables are interrelated between one entity and another. While DFD analysis serves as a tool to explain the flow of data in the system. ERD analysis system for forecasting DHF events refers to figure 2 . 


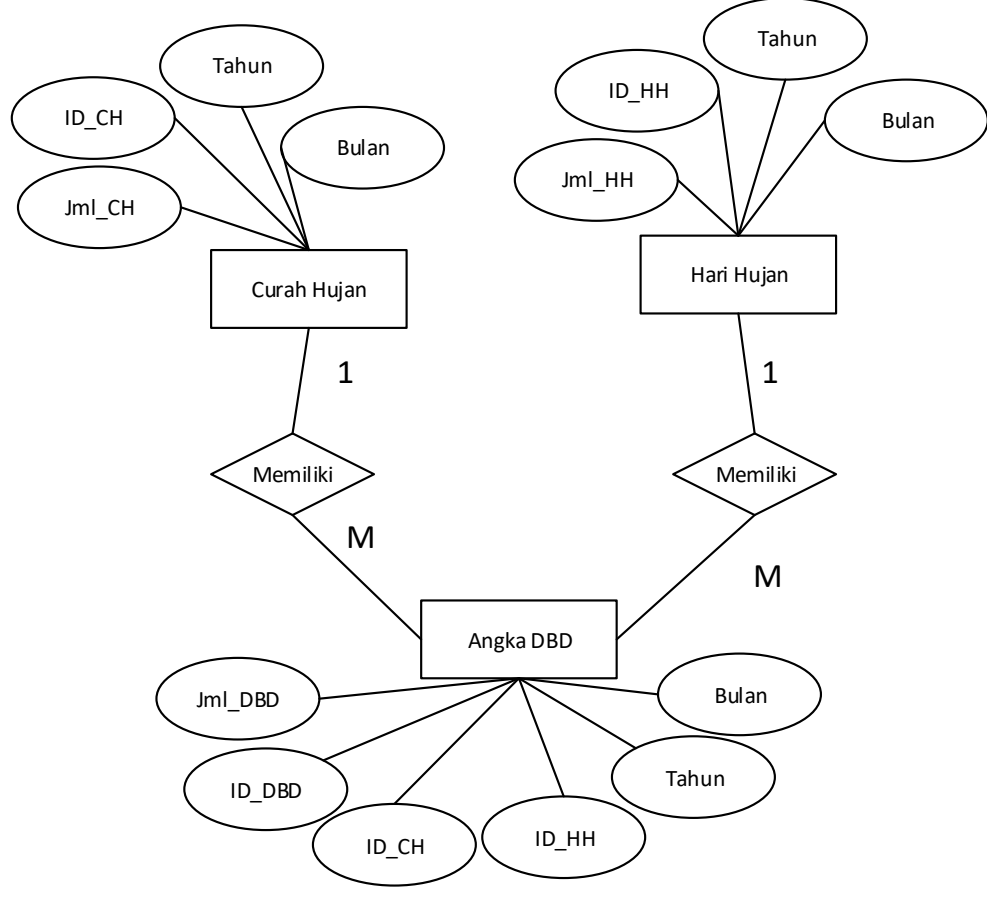

Fig. 2. Analysis of ERD system forecasting the number of DHF events

From the designed database there are 3 tables that have relationships between one another, namely the DHF event numbers table, rainfall, and rainy days. The following description of relations between tables is explained below:

a. Relation of rainfall table with DHF numbers

There is one attribute from the rainfall table that has a relation with one attribute in the DHF number table. The id_CH attribute in the DHF Figures table is derived from the rainfall table. The id_CH attribute in the rainfall table that has been run is then saved into the id_CH attribute in the DHF number table.

b. Relation of rainy day table with DHF numbers

There is one attribute from the rainy day table that has a relation to one attribute in the DHF number table. The id_HH attribute in the DHF Figures table comes from the rainy day table. The id_HH attribute in the rainy day table that has been run is then saved into the id_HH attribute in the DBD number table

B. DFD analysis

In the DFD analysis, there are two types of DFD designed, namely DFD Level 0 and DFD Level 1. DFD Level 0 is used to describe the overall system. Level 0 diagrams describe entities that are directly related to the system. DFD Level 0 of the estimated system of fish catches is shown in Figure 3.5. The function of DFD Level 1 is to define the functions of each data entity with detailed data flow on the system. DFD Level 1 system forecasting the incidence of DHF refers to Figure 3 


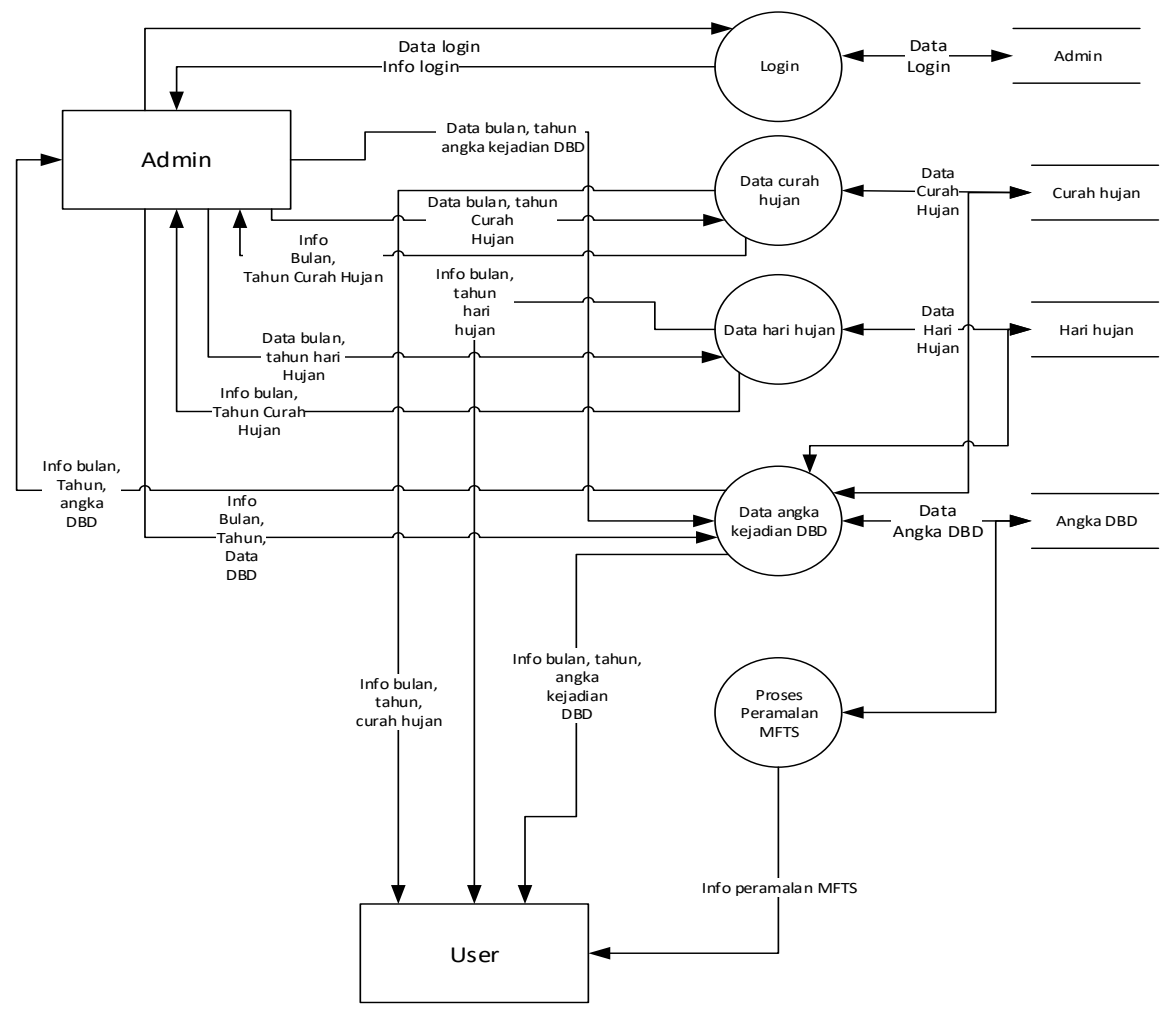

Fig. 3. DFD level 1 system forecasting the number of DHF events

Referring to Figure 3 DFD Level 1 system forecasting the number of DHF events described below:

1. The process of data flow on a system entity that occurs is the process of input data login. After the data input process is logged, the system will then validate the data in the admin database. If the username and password data is correct, the system displays an admin page that can be used to manage the data.

2. Furthermore, the process of data flow that occurs in the rainfall entity is done by entering the rainfall month and year of rainfall data. Then the data that has been inputted and then stored in a rainfall database. After that the system displays rainfall data on the forecasting system as information on rainfall data.

3. Furthermore, the process of data flow that occurs on rainy day entities is done by entering the data of rainy day month and year of rainy day. Then the data that has been inputted is then stored in the rainy day database. After that the system displays the rainy day data on the forecasting system as information on rainy day data.

4. The process of DHF event numbers is done by entering the month and year of rainfall data where the system takes data from the rainfall database, month and year data of DHF event numbers, and the month and year of rainy day data where the system takes data from the day database rain. Furthermore, the data is stored in the database of DHF event numbers and displayed in the forecasting system as information on DHF event numbers.

5. The process of forecasting the MFTS model for forecasting dengue event numbers is done by entering rainfall data. Then the system retrieves the data of rainy days and the number of DHF events in the database of DHF events. Then the system 
performs calculations using the MFTS model and the calculation results are displayed on the system in the form of forecasting information on the number of DHF events.Information System Framework

The information system framework is a physical description of an information system with some data which is an input of the system. There are several processes and outputs in the form of data that are displayed with several presentation models. The information system framework is represented in Figure 4

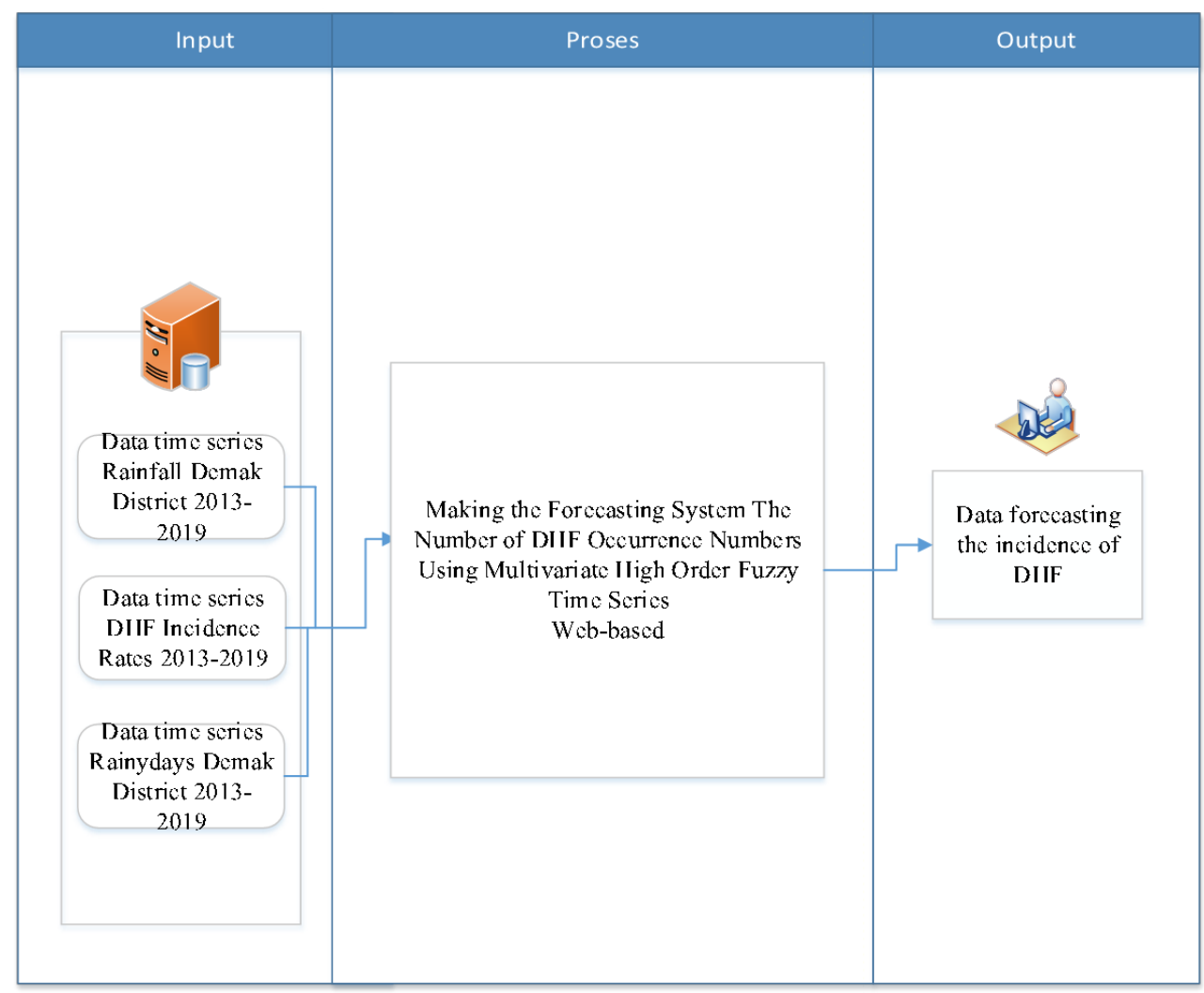

Fig. 4.The Forecasting Information Systems Framework.

\section{Research Result and Discussion}

Forecasting is done by using a scenario of two years, three years and four years. The results show that the lowest MAPE results are in the three-year scenario using data from January 2013 - January 2016. Based on the forecasting system that has been designed above, the results obtained as below table 3 : 
Table 3. Forcasting Result.

\begin{tabular}{|c|c|c|c|c|c|c|c|}
\hline Year & Month & DBD & $\mathrm{F} \%$ & Fdbd & Nilai Error & abs & APE \\
\hline 2013 & Jan & 101 & - & - & - & - & \\
\hline 2013 & Feb & 69 & - & - & - & - & \\
\hline 2013 & Mar & 64 & - & - & - & - & \\
\hline 2013 & Apr & 61 & - & - & - & - & \\
\hline 2013 & May & 75 & - & - & - & - & \\
\hline 2013 & Jun & 21 & - & - & - & - & \\
\hline 2013 & Jul & 26,00 & 25,00 & 26,25 & $-0,25$ & 0,25 & 0,96 \\
\hline 2013 & Aug & 49,00 & 75,00 & 45,50 & 3,50 & 3,50 & 7,14 \\
\hline 2013 & Sep & 58,00 & 25,00 & 61,25 & $-3,25$ & 3,25 & 5,60 \\
\hline 2013 & Oct & 32,00 & $-25,00$ & 43,50 & $-11,50$ & 11,50 & 35,94 \\
\hline 2013 & Nov & 15,00 & $-58,33$ & 13,33 & 1,67 & 1,67 & 11,11 \\
\hline 2013 & Dec & 39,00 & 158,33 & 38,75 & 0,25 & 0,25 & 0,64 \\
\hline 2015 & Jul & 68,00 & $-25,00$ & 63,00 & 5,00 & 5,00 & 7,35 \\
\hline 2015 & Aug & 56,00 & $-25,00$ & 51,00 & 5,00 & 5,00 & 8,93 \\
\hline 2015 & Sep & 25,00 & $-58,33$ & 23,33 & 1,67 & 1,67 & 6,67 \\
\hline 2015 & Oct & 27,00 & 25,00 & 31,25 & $-4,25$ & 4,25 & 15,74 \\
\hline 2015 & Nov & 41,00 & 75,00 & 47,25 & $-6,25$ & 6,25 & 15,24 \\
\hline 2015 & Dec & 43,00 & 25,00 & 51,25 & $-8,25$ & 8,25 & 19,19 \\
\hline 2016 & Jan & 88,00 & 125,00 & 96,75 & $-8,75$ & 8,75 & 9,94 \\
\hline & & & & & & & 332,6124 \\
\hline & & & & & MAPE & & 10,728 \\
\hline
\end{tabular}

From the results of the above study, the results obtained that the forecast value of the incidence of DHF by the MFTS method is strongly influenced by the number of orders. The higher the number of orders, the results of forecasting tend to get better, because the duplicate value of FLRG fuzzy set becomes less and less. The more ambiguity or duplication values a fuzzy set has, the more inaccurate the value of the forecast is. Besides forecasting results are also influenced by data fluctuations. The graph for forecasting DHF events in the 3-year scenario, shown in the figure below: 
느 Grafik Hasil Prediks

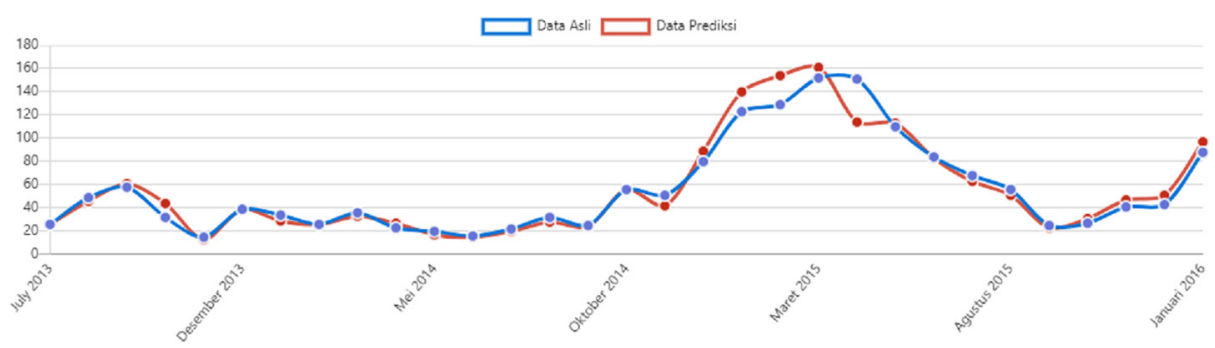

Fig. 5.The Forecasting Graph Result.

In the forecasting that has been done, it can be seen that the DHF incidence rate data is inconsistent with trends and has very high fluctuations, the main reason is the limited data provided from the District Health Office. And then, the number of DHF sufferers whose numbers fluctuate also occurs as a result by the health program carried out by the Demak District Health Office, namely the "Satu Rumah, Satu Jumantik" movement. The "Satu Rumah, Satu Jumantik" movement aims to reduce the number of DHF sufferers by increasing the participation and empowerment of family-based communities for prevention. The program succeeded in reducing the number of DHF events indicated by a decrease in the trend of DHF events every year. Therefore from that in 2014, 2017 and 2018 there was a drastic reduction in the incidence of DHF.

\section{Conclusion}

From the results of the above research, the following conclusions are obtained:

a. Forecasting of DHF disease rates processed using the Multivariate Fuzzy Time Series has an accurate accuracy. In some scenarios, the value of forecasting errors obtained is very high. This is caused by the variable number of DHF events which has very high fluctuations, so the resulting trend values become unnatural which results in inconsistencies in forecasting results.

b. The number of orders greatly affects the accuracy of forecasting using the Multivariate Fuzzy Time Series method in predicting with a large amount of data. Because the more data, the more duplication or ambiguity of the fuzzy set FLRG value. The higher the number of orders, the results of forecasting tend to get better, because the duplicate value of FLRG fuzzy set becomes less and less. The more ambiguity or duplication values a fuzzy set has, the more inaccurate the value of the forecast is.

c. Fluctuations in the incidence of dengue fever are influenced by several things, one of which is the health program carried out by the Demak District Health Office, namely the "Satu Rumah, Satu Jumantik" movement. The "Satu Rumah, Satu Jumantik" movement aims to reduce the number of DHF sufferers by increasing the participation and empowerment of family-based communities for prevention. The program succeeded in reducing the number of DHF events indicated by a decrease in the trend of DHF events every year.

The Multivariate Fuzzy Time Series (MFTS) method has several nuclei that influence forecasting results, namely the initiation of the formation of the universe set and the data interval values. This greatly affects the process of grouping fuzzy sets into FLRG which will affect the accuracy of forecasting done. Suggestions that researchers can give is to optimize the initiation of formation of the universal set. 


\section{References}

1. B. Yuan, H. Nishiura, Estimating the actual importation risk of dengue virus infection among Japanese travelers. PLoS One, 13, 1-12 (2018).

2. B.P. Statistik Kabupaten Demak . Demak in Figures 2016. (2016).

3. J. Xiang, A. Hansen, Q. Liu, X. Liu, M. Xiaoliang Tong, Y. Sun, S. Cameron, S. Hanson-Easey, G.Soo Han, C. Williams, P. Weinstein, Peng Bi, Association between dengue fever incidence and meteorological factors in Guangzhou, China, 2005-2014. Environ Res.,153, 17-26 (2017).

4. R. Lowe, A. Gasparrini, C.J. Van Meerbeeck, Catherine A. Lippi, R. Mahon, A.R. Trotman, L. Rollock, A.Q. J. Hinds, S.J. Ryan, Anna M. Stewart-Ibarra, Nonlinear and delayed impacts of climate on dengue risk in Barbados: A modelling study. PLoS Med., 15, 1-24 (2018).

5. W. Anggraeni, R. Nurmasari, E. Riksakomara, F. Samopa, R. Prasetyanto Wibowo, L. Condro T., Pujiadi, Modified Regression Approach for Predicting Number of Dengue Fever Incidents in Malang Indonesia, 4th Information Systems International Conference 2017, ISICO 2017, 50, 124-142 (2017)

6. R. Putranda Kristianto, E. Utami, Optimization the parameter of forecasting algorithm by using the genetical algorithm toward the information systems of geography for predicting the patient of dengue fever in district of sragen, Indonesia. Proc - 2017 2nd Int Conf Inf Technol Inf Syst Electr Eng ICITISEE 2017, 124, 45-50 (2018).

7. P. Manivannan, Dr. P. Isakki @ Devi, Dengue fever prediction using K-means clustering algorithm, Proc 2017 IEEE Int Conf Intell Tech Control Optim Signal Process INCOS 2017, 1-5, (2018).

8. D. Saikia, J. Chandra Dutta, Early diagnosis of dengue disease using fuzzy inference system, Int Conf Microelectron Comput Commun MicroCom 2016, 16 (2016).

9. T. Rosli Bin Razak, M. Hermi Ramli, R. Abd. Wahab, Dengue notification system using fuzzy logic, Proceeding - 2013 Int Conf Comput Control Informatics Its Appl "Recent Challenges Comput Control Informatics" IC3INA 2013, 231-235 (2013)

10. T. Faisal, M. Nasir Taib, F. Ibrahim, Adaptive Neuro-Fuzzy Inference System for diagnosis risk in dengue patients, Expert Syst Appl, 39, $4483-4495$ (2012).

11. I P. Agus Aditya Pramana, W. Anggraeni , Peramalan Jumlah Kasus Demam Berdarah di Inference System. J Tek ITS, 5, 1-6 (2016).

12. T. Ahmed Jilani, S. Muhammad Aqil Burney, M-factor high order fuzzy time series forecasting for road accident data, Adv Soft Computer, 41, 246-254 (2007).

13. C. Chen Wang, Y. Hsien Tu, H. Lun Wong, The comparison between multivariate fuzzy time series and traditional time series modeling to forecasting China exports, 2009 4th Int Conf Innov Comput Inf Control ICICIC 2009, 1487-1490 (2009).

14. D. Kartini, H. Rusdiani, A. Farmadi, Analisis Pengaruh Banyak Orde pada Metode Multivariate High-Order Fuzzy Time Series untuk Prediksi Duga Muka Air Waduk, J Edukasi Dan Penelit Inform, 5, 1-9 (2019). 
15. I M. Candra Satria, I K. Gede Sukarsa, K. Jayanegara, Peramalan Jumlah Wisatawan Australia Yang Berkunjung Ke Bali Menggunakan Multivariat Fuzzy Time Series. E-Jurnal Matematika, 4, 1-8, (2015).

16. L. Wei Lee, L. Hui Wang, S. Ming Chen, Senior Member, IEEE, Y. Ho Leu, Handling Forecasting Problems Based on Two-Factors High-Order Fuzzy Time Series, IEEE TRANSACTIONS ON FUZZY SYSTEMS, 14, 468-477 (2006). 